\title{
Electrochemical Stripping of Atomic Oxygen on Single-Crystalline Platinum: Bridging Gas-Phase and Electrochemical Oxidation
}

\author{
Yi-Fan Huang and Marc T. M. Koper*(1) \\ Leiden Institute of Chemistry, Leiden University, Einsteinweg 55, PO Box 9502, 2300 RA Leiden, The Netherlands
}

Supporting Information

\begin{abstract}
To understand the interaction between Pt and surface oxygenated species in electrocatalysis, this paper correlates the electrochemistry of atomic oxygen on $\mathrm{Pt}$ formed in the gas phase with electrochemically generated oxygen species on a variety of single-crystal platinum surfaces. The atomic oxygen adsorbed on single-crystalline $\mathrm{Pt}$ electrodes, made by thermal dissociation of molecular oxygen, is used for voltammetry measurements in acidic electrolytes $\left(\mathrm{HClO}_{4}\right.$ and $\left.\mathrm{H}_{2} \mathrm{SO}_{4}\right)$. The essential knowledge of coverage, binding energy, and surface construction of atomic oxygen is correlated with the charge, potential, and shape of voltammograms, respectively. The differences of the voltammograms between the oxide made by thermal dissociation of molecular oxygen and electrochemical oxidation imply that atomic oxygen is not an intermediate of the electrochemical oxidation of $\mathrm{Pt}(111)$. The reconstruction of (100) terrace and step and the low-potential stripping of atomic oxygen on (111) step site provide insight into the first stages of degradation of Pt-based electrocatalysts.
\end{abstract}

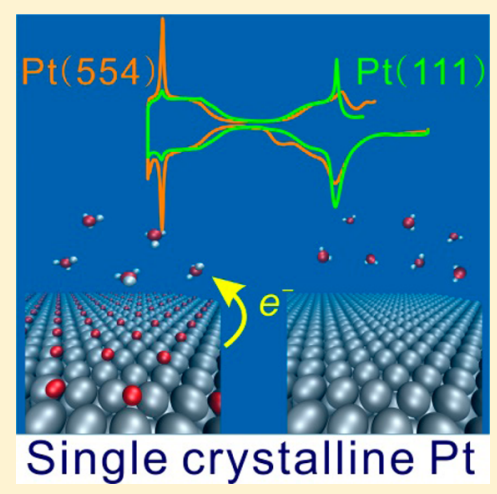

$\mathrm{P}$ latinum-based electrocatalysts are highly catalytic for the conversion cycles of carbon, nitrogen, and oxygen species. Catalyzing these redox cycles is becoming increasingly important regarding the urgent demands of industry, energy, and environment in modern society, such as the hydrogenoxygen fuel cell, water electrolysis, $\mathrm{CO}_{2}$ reduction, nitrate reduction, ammonia production, and so on. ${ }^{1-5}$ Because electrocatalysis is usually conducted in aqueous electrolyte, the platinum electrocatalyst may be covered by some intermediate stage of $\mathrm{Pt}$ surface oxide, for instance, during oxidation reactions or during the oxygen reduction reaction (ORR). The long-term degradation of the catalytic activity of a Pt electrocatalyst is thought to be related to the formation of this Pt oxide. ${ }^{6}$ Thus the surface oxygenated species or surface oxide that forms on $\mathrm{Pt}$ has attracted great attention and has been intensively studied in the past decades. $3,7,8$

The large number of investigations on the oxidation of $\mathrm{Pt}$ can be categorized in two groups, that is, ultrahigh vacuum (UHV)based surface science studies and electrochemical studies. In particular, surface science studies have established a detailed and systematic understanding of the oxidation of singlecrystalline Pt on the atomic scale. ${ }^{7}$ On the basis of Clavilier's pioneering work of preparing single-crystalline electrodes by flame annealing, single-crystalline Pt has also been intensively studied in electrocatalysis. ${ }^{9,10}$ However, while most surface science studies are conducted in a UHV chamber (although recent work on the oxidation of $\mathrm{Pt}(111)$ at higher oxygen pressure exists $\left.{ }^{11}\right)$, electrochemical studies are conducted in an aqueous electrolyte under ambient conditions, making these two cases of $\mathrm{Pt}$ surface oxidation drastically different. Importantly, the electrochemical oxidation of $\mathrm{Pt}$ involves $\mathrm{H}_{2} \mathrm{O}$, whereas $\mathrm{Pt}$ in vacuum or gas phase is oxidized by $\mathrm{O}_{2}$, $\mathrm{NO}_{2}$, or other active oxygen species. Thus it is highly desirable to understand the differences between the oxidation at the $\mathrm{Pt}$ / gas interface and the Pt/electrolyte interface. Attempts have been made to correlate the structure of the oxygenated species on $\mathrm{Pt}(111)$ /vacuum with surface oxygen species prepared by electrochemical oxidation on $\mathrm{Pt}(111){ }^{12}$ Many of the species involved have also been considered as intermediates in the oxygen reduction reaction (ORR). ${ }^{13}$ Understanding the nature of the surface species and their binding energetics at the singlecrystal Pt electrode surface is of paramount importance in surface electrochemistry and electrocatalysis. ${ }^{3}$ Unfortunately, these correlations are not straightforwardly verified by experiment, as there is little direct spectroscopic evidence of surface oxygen species; therefore, many correlations are actually based on (idealized) density functional theory (DFT) calculations. $^{12-14}$ Remarkably, our recent in situ shell-isolated nanoparticle-enhanced Raman spectroscopic (SHINERS) measurements suggested that the electrochemical oxidation of $\mathrm{Pt}(111)$ yields a 2D (su)peroxide surface layer, in stark disagreement with the expectation of the formation of atomic oxygen. ${ }^{15}$ This result suggested that there may be significant differences between gas-phase and electrochemical oxidation of platinum surfaces that have hitherto not been fully appreciated. Specifically, the participation of atomic oxygen in electrochemical oxidation is under discussion.

To shed further light on this issue, we propose here to measure the electrochemical stripping of atomic oxygen on single-crystalline $\mathrm{Pt}$ and compare it to the voltammetric features of electrochemical oxidation. The idea is to generate (atomic)

Received: January 18, 2017

Accepted: February 22, 2017

Published: February 22, 2017 
oxygen on single-crystalline Pt by bringing the Pt single crystal into contact with a molecular oxygen atmosphere $\left(\mathrm{O}_{2}\right)$ at ambient temperature and pressure (generating a species that we will refer to as $\left.\mathrm{Pt}-\mathrm{O}_{\mathrm{GAS}}\right)$. The fingerprint reductive stripping voltammogram of the atomic oxygen can be used to compare to the electrochemical characteristics of electrochemically generated oxygen species $\left(\mathrm{Pt}-\mathrm{O}_{\mathrm{EC}}\right)$ to draw conclusions regarding the nature of the oxygen species, coverage, binding energy, surface sites, surface reconstruction, and so on. In this way, the comparison of the reductive voltammograms of atomic oxygen on $\mathrm{Pt}$, prepared by thermal dissociation of molecular oxygen, and electrochemical oxidation will allow us to analyze the oxygenated species in intermediate stages of electrochemical oxidation of Pt.

We prepare the $\mathrm{Pt}_{\mathrm{t}} \mathrm{O}_{\mathrm{GAS}}$ electrode by contacting a flameannealed Pt crystal with a purely $\mathrm{O}_{2}$ atmosphere. Because investigations of thermal dissociation of $\mathrm{O}_{2}$ on $\mathrm{Pt}(111)$ by UHV show that the coverages of $\mathrm{O}$ generated at 420 and $620 \mathrm{~K}$ are different, ${ }^{16}$ first the effect of the crystal temperature during cooling in $\mathrm{O}_{2}$ atmosphere is carefully measured and controlled to avoid deformation of the surface (see Experimental Methods section and Supporting Information for details.) After cooling in oxygen, the Pt-O $\mathrm{O}_{\mathrm{GAS}}$ electrode is protected by a droplet of electrolyte-free water. The open-circuit potential of the $\mathrm{Pt}(111)-\mathrm{O}_{\mathrm{GAS}}$ measured under this condition is ca. $1.17 \mathrm{~V}$ (vs RHE). To ensure the stability of the $\mathrm{Pt}(111)-\mathrm{O}_{\mathrm{GAS}}$ upon transfer to the electrochemical cell, we set the starting potential of voltammetric scan to be $1.15 \mathrm{~V}$ to avoid (further) electrochemical oxidation or reduction. At the moment that the crystal contacts the electrolyte, we observed only a transient charging current, which suggests that the surface of $\mathrm{Pt}(111)$ $\mathrm{O}_{\mathrm{GAS}}$ is indeed stable at $1.15 \mathrm{~V}$.

Figure 1 shows the reductive stripping voltammograms of the $\mathrm{Pt}(111)-\mathrm{O}_{\mathrm{GAS}}$ with a cooling time of $10 \mathrm{~min}$ in $0.1 \mathrm{~mol} / \mathrm{L}$

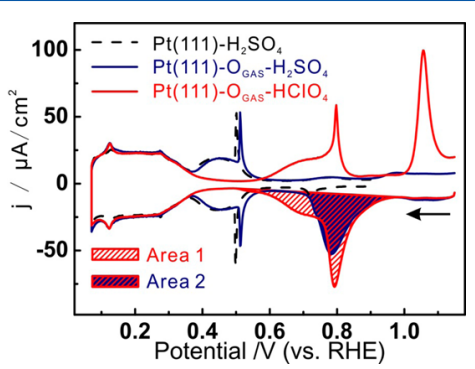

Figure 1. Voltammograms of $\mathrm{Pt}(111)-\mathrm{O}_{\mathrm{GAS}}$ and $\mathrm{Pt}(111)$ in $0.1 \mathrm{~mol} / \mathrm{L}$ $\mathrm{HClO}_{4}$ and $\mathrm{H}_{2} \mathrm{SO}_{4}$; the voltammetry of the $\mathrm{Pt}(111)-\mathrm{O}_{\mathrm{GAS}}$ starts at $1.15 \mathrm{~V}$ with a scan rate of $50 \mathrm{mV} / \mathrm{s}$.

$\mathrm{HClO}_{4}$ (red curve) and $0.1 \mathrm{~mol} / \mathrm{L} \mathrm{H}_{2} \mathrm{SO}_{4}$ electrolytes (blue curve) in comparison with the blank voltammetry of $\mathrm{Pt}(111)$ in sulfuric acid (black dashed line). It is clearly observed in Figure 1 that the reduction features observed between 1.0 and $0.6 \mathrm{~V}$ of the $\mathrm{Pt}(111)-\mathrm{O}_{\mathrm{GAS}}$, indicated by Area $1\left(\mathrm{HClO}_{4}\right)$ and Area 2 $\left(\mathrm{H}_{2} \mathrm{SO}_{4}\right)$, are significantly different from the $\mathrm{Pt}(111)$. We ascribe this current to the reductive stripping of $\mathrm{O}_{\mathrm{GAS}}$. Before we discuss the nature of this reductive stripping in more detail, we note that at potentials negative to $0.4 \mathrm{~V}$ the voltammograms for all three electrodes overlap, which indicates that the $\mathrm{Pt}(111)-\mathrm{O}_{\mathrm{GAS}}$ has been completely reduced. In the $\mathrm{H}_{2} \mathrm{SO}_{4}$ electrolyte, the voltammetric features of $\mathrm{Pt}(111)-\mathrm{O}_{\mathrm{GAS}}$ between 0.4 and $0.6 \mathrm{~V}$ are identical with $\mathrm{Pt}(111)$, which implies similar adsorption/desorption of bisulfate $\left(\mathrm{HSO}_{4}^{-}\right)$. The small peak from the $\{111\}$-type defects at ca. $0.12 \mathrm{~V}$ is also observed on the $\mathrm{Pt}(111)-\mathrm{O}_{\mathrm{GAS}}$ electrode, which indicates that the surface of $\mathrm{Pt}(111)-\mathrm{O}_{\mathrm{GAS}}$ is clean. Area 1 in $\mathrm{HClO}_{4}$ and Area 2 in $\mathrm{H}_{2} \mathrm{SO}_{4}$ are assigned to the stripping $\mathrm{O}_{\mathrm{GAS}}\left(\mathrm{Pt}(111)-\mathrm{O}_{\mathrm{GAS}}+2 \mathrm{H}^{+}+2 \mathrm{e}^{-}\right.$ $\rightarrow \mathrm{Pt}(111)+\mathrm{H}_{2} \mathrm{O}$; see the mechanistic analysis in the Supporting Information). According to the charge of the stripping charge of $\mathrm{O}_{\mathrm{GAS}}$ and $\mathrm{HSO}_{4}^{-}$, we conclude that the coverage of $\mathrm{O}_{\mathrm{GAS}}$ is $\sim 0.336$ (See Supporting Information), which is reasonably consistent with the measurement of $0.4 \mathrm{ML}$ on $\mathrm{Pt}(111)$ oxidized in 0.5 Torr $\mathrm{O}_{2} \cdot{ }^{11}$ We will assume that the $\mathrm{O}_{\mathrm{GAS}}$ layer formed is a layer of atomic oxygen, as assumed in the determination of the coverage, for which we will give further arguments in the remainder of the paper.

Temperature-programmed desorption of atomic oxygen to $\mathrm{O}_{2}$ (TPD- $\mathrm{O}_{2}$ ) is a widely used technique to study the interaction between the $\mathrm{Pt}$ surface and atomic oxygen, giving insight into the binding energy and the coverage. We will use here stripping voltammetry as a potential-programmed desorption of atomic oxygen on $\mathrm{Pt}(h k l)$ surfaces. For example, in the TPD- $\mathrm{O}_{2}$ measurement of $\mathrm{Pt}(553)-\mathrm{O}_{\mathrm{GAS}}$ generated in $\mathrm{UHV}$, the desorption temperature of oxygen atoms adsorbed on the step is higher than oxygen on the terrace, which indicates a higher binding energy of atomic oxygen at step edges. ${ }^{17}$ According to the reaction equation $\mathrm{Pt}(111)-\mathrm{O}_{\mathrm{GAS}}+$ $2 \mathrm{H}^{+}+2 \mathrm{e}^{-} \rightarrow \mathrm{Pt}(111)+\mathrm{H}_{2} \mathrm{O}$, the stripping potential directly describes the binding energy of the atomic oxygen versus the reference reaction $\left(\mathrm{H}^{+}+\mathrm{e}^{-} \leftrightarrows 1 / 2 \mathrm{H}_{2}\right)$ in an electrochemical environment, which allows us to compare binding energies in UHV and electrochemistry. ${ }^{18}$ Figure 2 a compares voltammo-
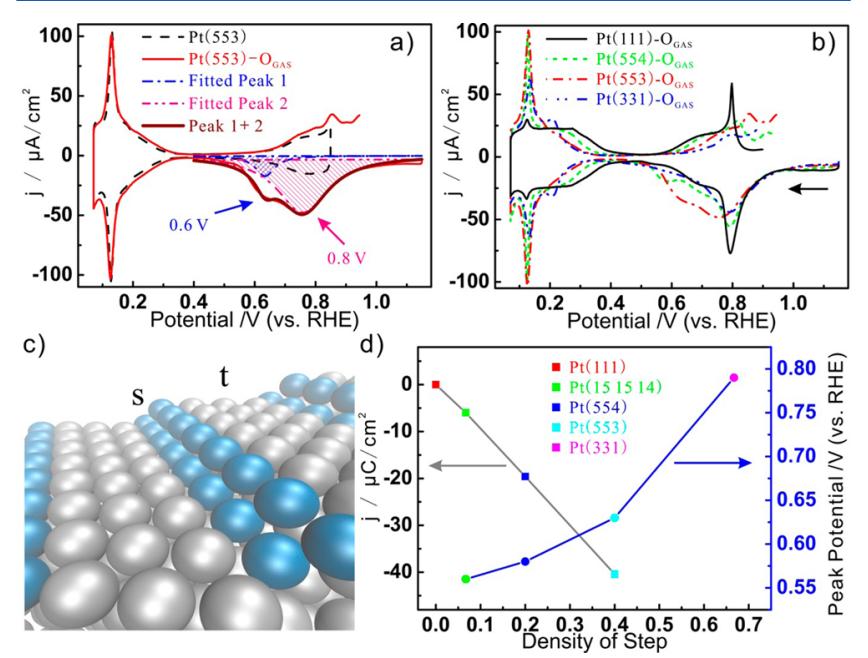

Figure 2. (a) Voltammograms of $\mathrm{Pt}(553)-\mathrm{O}_{\mathrm{GAS}}$ and $\mathrm{Pt}(553)$.(b) Voltammograms of $\mathrm{Pt}(111)-\mathrm{O}_{\mathrm{GAS}}, \mathrm{Pt}(554)-\mathrm{O}_{\mathrm{GAS}}, \mathrm{Pt}(553)-\mathrm{O}_{\mathrm{GAS}}$, and $\mathrm{Pt}(331)-\mathrm{O}_{\mathrm{GAS}}$. (c) Illustration of step and terrace atoms on $\mathrm{Pt}(553)$. (d) Peak potential and integrated charge of stripping voltammograms of $\mathrm{Pt}(\mathrm{s})-[n(111) \times(111)]-\mathrm{O}_{\mathrm{GAS}}$. All of the measurements were performed in $0.1 \mathrm{M} \mathrm{HClO}_{4}$ with a scan rate of $50 \mathrm{mV} / \mathrm{s}$.

grams of $\mathrm{Pt}(553)-\mathrm{O}_{\mathrm{GAS}}$ and $\mathrm{Pt}(553)$ in $0.1 \mathrm{~mol} / \mathrm{L} \mathrm{HClO}_{4}$ electrolyte. The standard voltammograms of the underpotential deposition hydrogen (UPD-H) region negative of $0.4 \mathrm{~V}$ on $\mathrm{Pt}(553)$ and $\mathrm{Pt}(553)-\mathrm{O}_{\mathrm{GAS}}$ overlap, which indicates that the adsorption of atomic oxygen does not lead to the creation of more defects. The stripping peak of oxygen on $\mathrm{Pt}(553)-\mathrm{O}_{\mathrm{GAS}}$ exhibits two peaks centered at 0.6 and $0.8 \mathrm{~V}$, which we will refer to as peaks 1 and 2, respectively. Figure $2 b$ shows a series of stripping voltammograms of $\mathrm{Pt}(\mathrm{s})-[n(111) \times$ 
(111) $]-\mathrm{O}_{\mathrm{GAS}}$ for varying terrace width $n$. Note that the stripping of $\mathrm{O}_{\mathrm{GAS}}$ from the stepped surfaces overlaps with a broad feature between 0.6 and $0.8 \mathrm{~V}$, which is ascribed to the reduction of $\mathrm{OH}$ from (111) terraces. ${ }^{19,20}$ To demonstrate the facet dependence of the stripping of atomic oxygen, the stripping peak is deconvoluted as shown in Figure 2a. The fraction of step sites to the total number of surface sites is defined as $s /(s+$ $t)$, as illustrated in Figure $2 \mathrm{c}$. Figure $2 \mathrm{~d}$ shows the charge density corresponding to peak 1 and the potential of peak 1 on $\mathrm{Pt}(\mathrm{s})-[n(111) \times(111)]-\mathrm{O}_{\mathrm{GAS}}$ as a function of the fraction of step sites. First, the charge density of peak 1 linearly depends on the step fraction, on the basis of which we assign peaks 1 and 2 to the stripping of atomic oxygen on the step and terrace sites, respectively. This assignment is also supported by DFT calculations of the binding energy of oxygen on the step site, showing that on $\mathrm{Pt}(553)$ step-site oxygen is $\sim 0.37 \mathrm{eV}$ more stable than terrace-site oxygen, ${ }^{21}$ which would correspond to a $0.185 \mathrm{~V}$ difference in stripping potential, in good agreement with experiment. Second, the peak potential shifts positively with increasing step site fraction, which we ascribe to step-step interactions (meaning that oxygen on isolated steps is more stable).

To further illustrate the correlation with UHV characterization, we also performed the measurements on $\mathrm{Pt}(100)-\mathrm{O}_{\mathrm{GAS}}$, where we note that the $\operatorname{Pt}(100)-(1 \times 1)$ surface is usually reconstructed by the adsorption of oxygenated species. ${ }^{22}$ Figure $3 \mathrm{a}$ shows the stripping voltammograms on $\mathrm{Pt}(100)-\mathrm{O}_{\mathrm{GAS}}$ (red
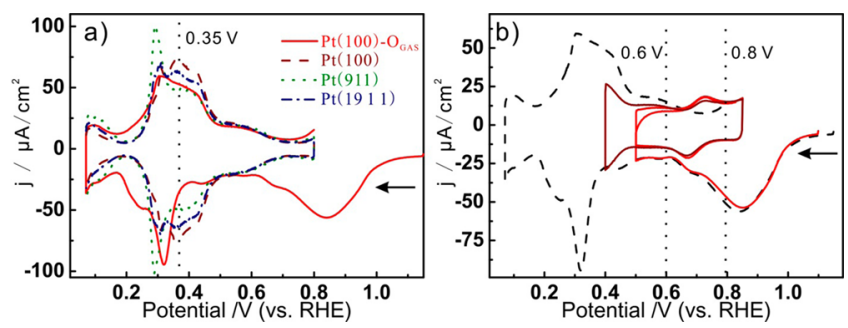

Figure 3. (a) Stripping voltammograms of $\mathrm{Pt}(100)-\mathrm{O}_{\mathrm{GAS}}$ and standard voltammograms of $\mathrm{Pt}(100), \operatorname{Pt}(1911)$, and $\mathrm{Pt}(911)$. (b) Low vertex potential dependent stripping voltammogram of $\mathrm{Pt}(100)-\mathrm{O}_{\mathrm{GAS}}$. All measurements were performed in $0.1 \mathrm{M} \mathrm{HClO}_{4}$ with a scan rate of 50 $\mathrm{mV} / \mathrm{s}$.

curve), where the broad peak centered at ca. $0.9 \mathrm{~V}$ is assigned to the stripping of oxygen. The voltammetric profile observed after oxygen stripping suggests that the adsorption of atomic oxygen indeed caused a surface reconstruction based on the following observations. First, the voltammogram is not symmetric at potentials negative of $0.5 \mathrm{~V}$. In particular, the cathodic current is lower than the corresponding anodic current in the potential region between 0.35 and $0.5 \mathrm{~V}$, which is assigned to the formation of $\mathrm{OH}$ on $\mathrm{Pt}(100){ }^{3,23}$ Second, it has been found that the reconstruction at room temperature is a transient complex surface structure between the $\mathrm{Pt}(100)-(1 \times$ 1) and the reconstructed $\operatorname{Pt}(100)-(1 \times 3)$ superstructure. ${ }^{24,25}$ Comparing $\mathrm{Pt}(100)-\mathrm{O}_{\mathrm{GAS}}$ with the standard voltammograms of $\operatorname{Pt}(100), \operatorname{Pt}\left(\begin{array}{lll}19 & 1 & 1\end{array}\right)$, and $\operatorname{Pt}(9 \quad 11)$, the current between 0.35 and $0.45 \mathrm{~V}$ decreases with increasing step density, which indicates that the adsorption of oxygen on $\mathrm{Pt}(100)-(1 \times 1)$ causes a partial deformation of the (100) terrace. Finally, on $\mathrm{Pt}(100)-\mathrm{O}_{\mathrm{GAS}}$ there is a redox couple in the potential region between 0.6 and $0.8 \mathrm{~V}$, as shown in Figure $3 \mathrm{~b}$. This redox couple is manifested only if the potential remains above $0.5 \mathrm{~V}$, so that the surface reconstruction is not lifted by UPD-H adsorption. We ascribe this feature to $\mathrm{OH}$ formation on hexagonally reconstructed parts of the surface. The reconstruction of the $\{100\}$ step can be also observed for $\mathrm{Pt}(533)$ $\mathrm{O}_{\mathrm{GAS}}$ surface. (See the Supporting Information.)

We will now discuss the difference between the oxygen species on $\mathrm{Pt}(111)$ made by thermal dissociation of $\mathrm{O}_{2}$ $\left(\mathrm{Pt}(111)-\mathrm{O}_{\mathrm{GAS}}\right)$ and the oxygen species generated by electrochemical oxidation $\left(\mathrm{Pt}(111)-\mathrm{O}_{\mathrm{EC}}\right)$. For $\mathrm{Pt}(111)-\mathrm{O}_{\mathrm{EC}}$, the coverage of oxygen and the nature of the surface oxygen species on Pt depends on the applied oxidation potential. Let us first discuss the oxygen species formed at $1.15 \mathrm{~V}(\mathrm{Pt}(111)$ $\left.\mathrm{O}_{\mathrm{EC}, 1.15 \mathrm{~V}}\right)$. It is generally agreed that the peak at $0.8 \mathrm{~V}$ corresponds to the formation of $\mathrm{OH}_{\text {ads }}$ on the $\mathrm{Pt}(111)$. This surface hydroxyl phase is oxidized in a peak at $1.07 \mathrm{~V}$. On the basis of in situ SHINERS measurements, we recently proposed that the $\mathrm{Pt}(111)-\mathrm{O}_{\mathrm{EC}}$ formed in this peak corresponds to a form of surface (su)peroxide on $\mathrm{Pt}(111)$ rather than to atomic oxygen on $\mathrm{Pt}(111)$, as was previously suggested. ${ }^{15}$ In Figure $4 \mathrm{a}$

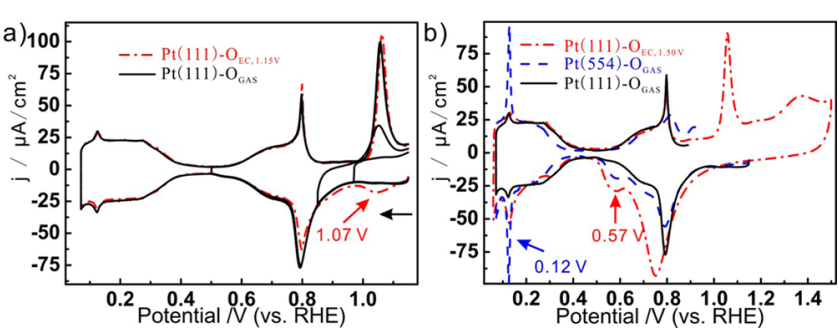

Figure 4. (a) Voltammograms of $\mathrm{Pt}(111)-\mathrm{O}_{\mathrm{GAS}}$ and $\mathrm{Pt}(111)-\mathrm{O}_{\mathrm{EC}, 11.15 \mathrm{~V}}$. (b) Voltammograms of $\mathrm{Pt}(111)-\mathrm{O}_{\mathrm{GAS}}, \mathrm{Pt}(554)-\mathrm{O}_{\mathrm{GAS}}$, and $\mathrm{Pt}(111)-$ $\mathrm{O}_{\mathrm{EC}, 1.50 \mathrm{~V}}$ in $0.1 \mathrm{~mol} / \mathrm{L} \mathrm{HClO}_{4}$ electrolyte (scan rate: $50 \mathrm{mV} / \mathrm{s}$ ).

we compare the reductive stripping voltammograms of $\mathrm{Pt}(111)-\mathrm{O}_{\mathrm{GAS}}$ and $\mathrm{Pt}(111)-\mathrm{O}_{\mathrm{EC}, 1.15 \mathrm{~V}}$ in $\mathrm{HClO}_{4}$ electrolyte. We note that the cathodic peak at ca. $1.05 \mathrm{~V}$ for $\mathrm{Pt}(111)-\mathrm{O}_{\mathrm{EC}}$ is not observed on $\mathrm{Pt}(111)-\mathrm{O}_{\mathrm{GAS}}$, which is a first indication that $\mathrm{Pt}(111)-\mathrm{O}_{\mathrm{EC}}$ is different from $\mathrm{Pt}(111)-\mathrm{O}_{\mathrm{GAS}}$. This cathodic peak is apparently associated with the anodic peak at $1.07 \mathrm{~V}$, as can be observed when oxygen is stripped from $\mathrm{Pt}(111)-\mathrm{O}_{\mathrm{GAS}}$ until $0.9 \mathrm{~V}$ and then scanned positively again (see Figure $4 \mathrm{a}$ ). The potential of the anodic peak at $1.07 \mathrm{~V}$ shifts negatively in more alkaline electrolyte, ${ }^{3}$ which implies that it may correspond to the reduction of a negatively charged oxygen species. ${ }^{15}$ The irreversibility of the stripping of the oxygen species of $\mathrm{Pt}(111)$ $\mathrm{O}_{\mathrm{EC}}$ generated at $1.07 \mathrm{~V}$ is not fully understood. According to Gómez-Marín and Feliu, the irreversibility is kinetic in origin and related to a slow nucleation-and-growth mechanism. ${ }^{26}$ The significant conclusion of our work here is that the oxygen species generated in $\mathrm{Pt}(111)-\mathrm{O}_{\mathrm{GAS}}$ has no counterpart in $\mathrm{Pt}(111)-\mathrm{O}_{\mathrm{EC}}$, confirming our previous conclusion that the atomic oxygen is not an intermediate in the electrochemical oxidation of $\mathrm{Pt}(111) .^{15}$

When the potential of electrochemical oxidation is scanned more positive than $1.2 \mathrm{~V}$, the oxide formed is different from that negative of $1.2 \mathrm{~V}$, and the well-defined $\mathrm{Pt}(111)$ surface is irreversibly damaged. ${ }^{26}$ Figure $2 \mathrm{~b}$ compares the stripping voltammograms of $\mathrm{Pt}(111)-\mathrm{O}_{\mathrm{GAS}}, \mathrm{Pt}(554)-\mathrm{O}_{\mathrm{GAS}}$, and $\mathrm{Pt}(111)-\mathrm{O}_{\mathrm{EC}, 1.50 \mathrm{~V}}$ in $0.1 \mathrm{~mol} / \mathrm{L} \mathrm{HClO}_{4}$ electrolyte. It can be seen that the voltammograms of $\mathrm{Pt}(554)-\mathrm{O}_{\mathrm{GAS}}$ and $\mathrm{Pt}(111)$ $\mathrm{O}_{\mathrm{EC}, 1.50 \mathrm{~V}}$ both show peaks at 0.57 and $0.12 \mathrm{~V}$, which implies the formation of adsorbed atomic oxygen and adsorbed hydrogen on (111) type step edges formed on $\mathrm{Pt}(111)-\mathrm{O}_{\mathrm{EC}, 1.50 \mathrm{~V}}$. 
According to the charges of 33.4 and $16.0 \mu \mathrm{C} / \mathrm{cm}^{2}$ of the peaks at 0.57 and $0.12 \mathrm{~V}$, respectively, we estimate the defect density to be ca. 0.2 from the step density plot in Figure $2 \mathrm{~d}$. The stepedge features of $\mathrm{Pt}(111)-\mathrm{O}_{\mathrm{EC}, 1.50 \mathrm{~V}}$ are broader than those of stepped surfaces, suggesting that the defects are much more random and heterogeneous than regular step edges.

In summary, we have measured the stripping voltammograms of atomic oxygen on various single-crystal Pt electrodes, as generated by the dissociation of molecular oxygen at room temperature. The coverage of atomic oxygen on $\mathrm{Pt}(111)$ was measured to be ca. 0.33, as concluded from the stripping charge. The stripping potential of atomic oxygen from the stepedge and terrace sites on $\mathrm{Pt}(\mathrm{s})-[n(111) \times(111)]$ agrees with the expected binding energy difference; that is, the oxygen adsorbed on the $\{111\}$ step type has a ca. $0.37 \mathrm{eV}$ higher binding energy and is stripped at ca. $0.2 \mathrm{~V}$ more negative potential compared with atomic oxygen on the terrace. The stripping measurements on $\mathrm{Pt}(\mathrm{s})-[n(100) \times(111)]$ surfaces indicate the reconstruction of $\{100\}$ terrace and step sites caused by adsorption of oxygen, leading to a mixture of $\{100\}$ terrace and $\{111\}$-type domains on the surface. The comparison between the reductive voltammograms of the oxygen on $\mathrm{Pt}(111)$ made by thermal dissociation of molecular oxygen and electrochemical oxidation at $1.15 \mathrm{~V}$ suggests that electrochemical oxidation of $\mathrm{Pt}(111)$ does not lead to atomic oxygen state on $\mathrm{Pt}(111)$, consistent with our previous SHINERS measurements showing the formation of a surface (su)peroxide phase instead. When $\mathrm{Pt}(111)$ is oxidized electrochemically at $1.5 \mathrm{~V}$, the surface disorders and leads to a reduction peak that is very similar to the stripping voltammograms of atomic oxygen from the step edges in $\operatorname{Pt}(s)-[n(111) \times(111)]$, indicating that atomic oxygen adsorbed on $\{111\}$ step sites appears to be an intermediate in electrochemical oxidation.

\section{EXPERIMENTAL METHODS}

The semibead-like single-crystalline $\mathrm{Pt}$ electrodes were purchased from iCryst. The electrolyte solutions of $\mathrm{HClO}_{4}$ and $\mathrm{H}_{2} \mathrm{SO}_{4}$ were prepared by $\mathrm{HClO}_{4}$ (70\%, Suprapur, Merck) and $\mathrm{H}_{2} \mathrm{SO}_{4}$ (96\%, Suprapur, Merck). The ultrapure water (resistivity $>18.2 \mathrm{M} \Omega \mathrm{cm}$ ) was produced by a Milli-Q gradient A10 system. The gases of $\mathrm{H}_{2}, \mathrm{O}_{2}$, and Ar with a purity grade of 6.0 (99.9999\%) were provided by Linde.

The $\mathrm{Pt}-\mathrm{O}_{\mathrm{GAS}}$ was prepared in a round-bottomed flask with a volume of $250 \mathrm{~mL}$ containing $\sim 150 \mathrm{~mL}$ of $\mathrm{O}_{2}$-saturated water without any electrolyte. The input gas flow goes through a trap of $3 \mathrm{M} \mathrm{NaOH}$ solution before it enters the flask. To avoid explosion, $\mathrm{H}_{2}$ is switched off after the Ar flow is increased slowly and the cap of the flask is released. Next, the $\mathrm{O}_{2}$ flow is switched on. To avoid the influence from any possible reaction on the thermal couple, we used pure Ar with a same flow rate as $\mathrm{H}_{2} / \mathrm{Ar}$ in the measurement of crystal temperature.

\section{ASSOCIATED CONTENT}

\section{S Supporting Information}

The Supporting Information is available free of charge on the ACS Publications website at DOI: 10.1021/acs.jpclett.7b00136.

Experimental details of $\mathrm{Pt}-\mathrm{O}_{\mathrm{GAS}}$ preparation including temperature dependence. $\mathrm{pH}$ dependence of stripping voltammogram and determination of $\mathrm{O}_{\mathrm{GAS}}$ coverage. Stripping voltammogram of $\mathrm{Pt}(533)-\mathrm{O}_{\mathrm{GAS}}$ ( $\mathrm{PDF}$ )

\section{AUTHOR INFORMATION}

\section{Corresponding Author}

*E-mail: m.koper@lic.leidenuniv.nl.

ORCID

Marc T. M. Koper: 0000-0001-6777-4594

Notes

The authors declare no competing financial interest.

\section{ACKNOWLEDGMENTS}

This work was financially supported by the European Commission Horizon 2020-Research and Innovation Framework Programme (Marie Skłodowska-Curie actions Individual Fellowship awarded to Y.-F.H., no. 661145, DYNECAT).

\section{REFERENCES}

(1) Canfield, D. E.; Glazer, A. N.; Falkowski, P. G. The Evolution and Future of Earth's Nitrogen Cycle. Science 2010, 330, 192-196.

(2) Debe, M. K. Electrocatalyst Approaches and Challenges for Automotive Fuel Cells. Nature 2012, 486, 43-51.

(3) Marković, N. M.; Ross, P. N., Jr Surface Science Studies of Model Fuel Cell Electrocatalysts. Surf. Sci. Rep. 2002, 45, 117-229.

(4) Tian, N.; Zhou, Z.-Y.; Sun, S.-G.; Ding, Y.; Wang, Z. L. Synthesis of Tetrahexahedral Platinum Nanocrystals with High-Index Facets and High Electro-Oxidation Activity. Science 2007, 316, 732-735.

(5) Rosca, V.; Duca, M.; de Groot, M. T.; Koper, M. T. M. Nitrogen Cycle Electrocatalysis. Chem. Rev. 2009, 109, 2209-2244.

(6) Zhang, S.; Yuan, X.-Z.; Hin, J. N. C.; Wang, H.; Friedrich, K. A.; Schulze, M. A Review of Platinum-Based Catalyst Layer Degradation in Proton Exchange Membrane Fuel Cells. J. Power Sources 2009, 194, $588-600$.

(7) Somorjai, G. A.; Li, Y. Introduction to Surface Chemistry and Catalysis, 2nd ed.; John Wiley \& Sons: Hoboken, NJ, 2010.

(8) Conway, B. E. Electrochemical Oxide Film Formation at Noble Metals as a Surface-Chemical Process. Prog. Surf. Sci. 1995, 49, 331452.

(9) Clavilier, J.; Faure, R.; Guinet, G.; Durand, R. Preparation of Monocrystalline Pt Microelectrodes and Electrochemical Study of the Plane Surfaces Cut in the Direction of the $\{111\}$ and $\{110\}$ Planes. J. Electroanal. Chem. Interfacial Electrochem. 1980, 107, 205-209.

(10) Climent, V.; Feliu, J. M. Thirty Years of Platinum Single Crystal Electrochemistry. J. Solid State Electrochem. 2011, 15, 1297-1315.

(11) Miller, D. J.; Öberg, H.; Kaya, S.; Sanchez Casalongue, H.; Friebel, D.; Anniyev, T.; Ogasawara, H.; Bluhm, H.; Pettersson, L. G. M.; Nilsson, A. Oxidation of $\mathrm{Pt}(111)$ under Near-Ambient Conditions. Phys. Rev. Lett. 2011, 107 (19), 195502.

(12) Gómez-Marín, A. M.; Feliu, J. M. Pt(111) Surface Disorder Kinetics in Perchloric Acid Solutions and the Influence of Specific Anion Adsorption. Electrochim. Acta 2012, 82, 558-569.

(13) Nørskov, J. K.; Rossmeisl, J.; Logadottir, A.; Lindqvist, L.; Kitchin, J. R.; Bligaard, T.; Jónsson, H. Origin of the Overpotential for Oxygen Reduction at a Fuel-Cell Cathode. J. Phys. Chem. B 2004, 108, 17886-17892.

(14) Tian, F.; Jinnouchi, R.; Anderson, A. B. How Potentials of Zero Charge and Potentials for Water Oxidation to $\mathrm{OH}(\mathrm{ads})$ on $\mathrm{Pt}(111)$ Electrodes Vary With Coverage. J. Phys. Chem. C 2009, 113, 1748417492.

(15) Huang, Y. F.; Kooyman, P. J.; Koper, M. T. M. Intermediate Stages of Electrochemical Oxidation of Single-Crystalline Platinum Revealed by in situ Raman spectroscopy. Nat. Commun. 2016, 7, 12440.

(16) Bashlakov, D. L.; Juurlink, L. B. F.; Koper, M. T. M.; Yanson, A. I. Subsurface Oxygen on $\mathrm{Pt}(111)$ and Its Reactivity for CO Oxidation. Catal. Lett. 2012, 142, 1-6.

(17) van der Niet, M. J. T. C.; den Dunnen, A.; Juurlink, L. B. F.; Koper, M. T. M. A Detailed TPD Study of H2O and Pre-adsorbed O 
on the Stepped Pt(553) Surface. Phys. Chem. Chem. Phys. 2011, 13, $1629-1638$.

(18) Koper, M. T. M. Blank voltammetry of hexagonal surfaces of Ptgroup metal electrodes: Comparison to Density Functional Theory Calculations and Ultra-high Vacuum Experiments on Water Dissociation. Electrochim. Acta 2011, 56, 10645-10651.

(19) Berná, A.; Climent, V.; Feliu, J. M. New Understanding of the Nature of $\mathrm{OH}$ Adsorption on $\mathrm{Pt}(111)$ Electrodes. Electrochem. Commun. 2007, 9, 2789-2794.

(20) Wakisaka, M.; Suzuki, H.; Mitsui, S.; Uchida, H.; Watanabe, M. Identification and Quantification of Oxygen Species Adsorbed on $\mathrm{Pt}$ (111) Single-Crystal and Polycrystalline Pt Electrodes by Photoelectron Spectroscopy. Langmuir 2009, 25, 1897-1900.

(21) Kolb, M. J.; Calle-Vallejo, F.; Juurlink, L. B. F.; Koper, M. T. M. Density Functional Theory Study of Adsorption of $\mathrm{H} 2 \mathrm{O}, \mathrm{H}, \mathrm{O}$, and OH on Stepped Platinum Surfaces. J. Chem. Phys. 2014, 140, 134708.

(22) Lang, B.; Légaré, P.; Maire, G. Adsorption Studies on the Pt (100) Surface. Surf. Sci. 1975, 47, 89-97.

(23) van der Niet, M. J. T. C.; Garcia-Araez, N.; Hernández, J.; Feliu, J. M.; Koper, M. T. M. Water Dissociation on Well-defined Platinum Surfaces: The Electrochemical Perspective. Catal. Today 2013, 202, $105-113$.

(24) Griffiths, K.; Jackman, T. E.; Davies, J. A.; Norton, P. R. Interaction of $\mathrm{O}_{2}$ with $\mathrm{Pt}(100)$. Surf. Sci. 1984, 138, 113-124.

(25) Kibler, L. A.; Cuesta, A.; Kleinert, M.; Kolb, D. M. In-situ STM characterisation of the Surface Morphology of Platinum Single Crystal Electrodes as a Function of Their Preparation. J. Electroanal. Chem. 2000, 484, 73-82.

(26) Gómez-Marín, A. M.; Clavilier, J.; Feliu, J. M. Sequential $\mathrm{Pt}$ (111) Oxide Formation in Perchloric Acid: an Electrochemical Study of Surface Species Inter-conversion. J. Electroanal. Chem. 2013, $688,360-370$. 